\title{
Effects of Zileuton on Airway Smooth Muscle Remodeling after Repeated Allergen Challenge in Brown Norway Rats
}

\author{
Wei-Ji Chen ${ }^{a}$ Shwu-Fang Liaw ${ }^{a}$ Ching-Chi Lin ${ }^{a} b \quad$ Mei-Wei Lin ${ }^{a}$ \\ Feng-Ting Chang ${ }^{\text {a }}$ \\ ${ }^{a}$ Chest Division, Departments of Internal Medicine and Medical Research, Mackay Memorial Hospital, and \\ ${ }^{b}$ Department of Nursing, Mackay Medicine, Nursing and Management College, Taipei, Taiwan, ROC
}

\section{Key Words}

Airway remodeling - Airway smooth muscle - Bronchial hyperreactivity $\cdot$ Leukotriene $\cdot$ Zileuton

\begin{abstract}
Background: Chronic asthma is characterized by airway inflammation and remodeling. Objective: This study aimed to evaluate the effects of zileuton on bronchial hyperresponsiveness, airway inflammation and airway smooth muscle (ASM) remodeling. Methods: Two experimental groups of brown Norway rats sensitized and repeatedly challenged with aerosolized ovalbumin $(\mathrm{OA})$ were given oral zileuton (OA-zileuton group) and oral saline only (OA-saline group). A third, control group was sensitized and challenged by saline. The rats were anesthetized and paralyzed. Pulmonary function tests were performed at baseline and after varying doses of acetylcholine. Bronchoalveolar lavage fluid and lung tissues were examined. Results: Zileuton had beneficial effects on pulmonary function, airway inflammation and ASM remodeling in the OA-zileuton group compared to the OA-saline group. Zileuton inhibited an OA-stimulated increase in ASM by inhibiting hypertrophy, hyperplasia and increased extracellular matrix via the phosphatidylinositol
\end{abstract}

\section{KARGER}

E-Mail karger@karger.com

www.karger.com/res
(C) 2013 S. Karger AG, Basel

0025-7931/13/0865-0421\$38.00/0 3-kinase (PI3K)/Akt pathway, thereby reducing cyclin D1 expression and attenuating bronchial hyperresponsiveness. Conclusion: OA increases airway inflammation and ASM mass. Zileuton effectively prevents bronchial hyperresponsiveness, airway inflammation and ASM remodeling in sensitized rats through the PI3K/Akt pathway, which reduces cyclin D1 expression.

(c) 2013 S. Karger AG, Basel

\section{Introduction}

Asthma is a combination of chronic airway inflammation and remodeling $[1,2]$. Increased airway smooth muscle (ASM) mass is the most important factor of airway remodeling, fixed airway obstruction and bronchial hyperreactivity (BHR) in severe asthma [3, 4]. Evidence has shown that increased ASM mass is the result of the response to inflammation in asthma. However, many antiasthmatic agents like corticosteroids are not very effective in decreasing ASM [5], which also has characteristics of inflammatory cells. ASM can produce various cytokines and chemokines that activate many different inflammatory cells and promote their survival and prolif- 
eration $[6,7]$. Remodeling of ASM may result from hypertrophy, hyperplasia or increased extracellular matrix $(\mathrm{ECM})[8,9]$. Both mammalian target of rapamycin (mTOR) and glycogen synthase kinase- $3 \beta$ (GSK-3 $\beta$ ) signal transduction mechanisms are involved in ASM hypertrophy [10]. The mTOR induces the phosphorylation of eukaryotic translation initiation factor (eIF) 4E-binding protein $(4 \mathrm{E}-\mathrm{BP})$, which releases the transcription factor eIF4E leading to ASM cell hypertrophy [11]. The mTOR also phosphorylates p70S6-kinase, which activates S6 kinase and induces ASM hypertrophy [12]. The latter may also involve Akt to inhibit GSK-3 $\beta$, which inhibits the translation initiation by eukaryotic initiation factor 2B (eIF2B) and induces ASM hypertrophy $[13,14]$.

Many factors can trigger ASM cell hyperplasia, such as growth factors/cytokines activating receptor tyrosine kinase, inflammatory mediators activating $\mathrm{G}$ protein-coupled receptors, reactive oxygen species and mechanical stress $[9,15]$. Activation of receptor tyrosine kinase or G protein-coupled receptors induces p21ras activation, which subsequently activates phosphatidylinositol 3-kinase (PI3K) and/or extracellular signal-regulated kinase (ERK). Increased PI3K expression of cyclin D1 leads to ASM cell hyperplasia $[16,17]$.

Cysteinyl leukotrienes are lipid mediators derived from the 5-lipoxygenase pathway of the arachidonic acid metabolism. They are produced by mast cells, eosinophils and alveolar macrophages, and are important mediators of bronchoconstriction, airway wall edema and mucous hypersecretion in asthmatic patients $[18,19]$. Their actions include enhancing histamine and cytokine release, recruiting inflammatory cells to the airways, and stimulating the proliferation of smooth muscle cells and fibroblasts [20].

Evidence has shown that cysteinyl leukotrienes play an important role in airway remodeling seen in persistent asthma that includes subepithelial fibrosis, elevated numbers and volume of mucous cells, increased ASM mass, and angiogenesis. Structural changes entail physiologic consequences, progressive loss of lung function and permanent, irreversible airway obstruction in some asthmatics [21].

Evidence also suggests that blocking the leukotriene pathway may result in reduced inflammation, thereby preventing airway remodeling $[20,22]$. Zileuton is a 5-lipoxygenase inhibitor [23]. This study aimed to evaluate the protective effect of zileuton on airway inflammation, T cell-related cytokine mRNA expression and ASM remodeling in rats sensitized and repeatedly challenged with ovalbumin (OA).

\section{Methods}

\section{Animals}

Thirty male brown Norway rats were divided into three groups of 10 weight-matched animals. Two experimental groups were sensitized by breathing $2 \mathrm{ml}$ of aerosolized 1\% OA on day 1 . On day 16 , the animals were challenged with OA six times with 3-day intervals. The control group breathed aerosolized saline rather than OA under the same conditions. The two experimental groups were also treated orally from days 1 to 30 with either zileuton (Chemax Corp, Shanghai, China) $25 \mathrm{mg} / \mathrm{kg} /$ day (OA-zileuton group) or normal saline (OA-saline group). When challenged, the experimental groups were provoked by breathing $3 \mathrm{ml}$ of $4 \%$ aerosolized OA delivered by nebulizer, with the control group breathing only aerosolized saline. The last challenge was on day 30. Analysis was performed on day 31 [24]. The Institutional Animal Care and Use Committee approved this study.

Study Protocol, Procedure and Pulmonary Function Tests

Pulmonary function and acetylcholine provocation tests were conducted under general anesthesia (chloral hydrate, $400 \mathrm{mg} / \mathrm{kg}$ via intraperitoneal injection) using whole-body plethysmograph $24 \mathrm{~h}$ after the final challenge on day 31 , as previously described [24]. For the experimental groups, the tests were done $24 \mathrm{~h}$ after the OA provocation test and, for the control group, $24 \mathrm{~h}$ after the final saline aerosolization. The animals were then paralyzed with intravenous gallamine triethiodide $(4 \mathrm{mg} / \mathrm{kg}$ ) and artificially ventilated with a small animal ventilator at $6 \mathrm{ml} / \mathrm{kg}$ tidal volume and a frequency of 60 breaths $/ \mathrm{min}$. All of the animals were stable without spontaneous breathing 5 min after gallamine injection.

Pulmonary function tests, including airway opening pressure during ventilator breathing, total respiratory system compliance and maximal forced expiratory maneuver, were measured at baseline. Thereafter, acetylcholine 25, 50, 75 and $100 \mu \mathrm{g} / \mathrm{kg}$ was given intravenously at 30-min intervals. Before each successive dose, airflow returned to baseline. Pulmonary function tests were done $5 \mathrm{~s}$ after each dose.

For maximal forced expiratory maneuver, the lungs were inflated to total lung capacity (TLC; lung volume at airway opening pressure: $30 \mathrm{~cm} \mathrm{H}_{2} \mathrm{O}$ ) three times, while a solenoid valve regulated the inflation. At peak volume on the third inflation, the valve was shut off and another solenoid valve was immediately opened for deflation. The deflation valve was connected to a 20-liter container at a pressure of $-30 \mathrm{~cm} \mathrm{H}_{2} \mathrm{O}$ (subatmospheric) such that the negative pressure produced maximal expiratory flow.

The variables recorded were the flow volume loop, including peak flow and maximal forced expiratory flow rate at $75 \%$ $\left(\mathrm{MFEF}_{75 \%}\right), 50 \%\left(\mathrm{MFEF}_{50 \%}\right)$ and $25 \%\left(\mathrm{MFEF}_{25 \%}\right)$ TLC. The

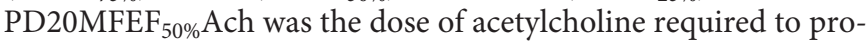
duce a $20 \%$ decrease in $\mathrm{MFEF}_{50 \%}$ from baseline. Bronchoalveolar lavage (BAL) was performed as previously described, before the rats were sacrificed and their trachea and lungs removed for histologic examination [24].

\section{Cytokine Levels in Lavage Fluid}

The concentrations of IL-10, IL-13, TGF- $\beta 1$ and vascular endothelial growth factor (VEGF) in BAL fluid were measured in duplicate and in blinded fashion using commercially available ratspecific TGF- $\beta 1$ and VEGF enzyme-linked immunosorbent assay (ELISA) kits (R\&D Systems, Minneapolis, Minn., USA), and IL-10 
and IL-13 ELISA kits (Invitrogen, Camarillo, Calif., USA). The detection limit was $<1.7 \mathrm{pg} / \mathrm{ml}$ for TGF- $\beta 1,<3.9 \mathrm{pg} / \mathrm{ml}$ for VEGF, $<5 \mathrm{pg} / \mathrm{ml}$ for IL- 10 and $<1.5 \mathrm{pg} / \mathrm{ml}$ for IL-13.

Prior to analysis, latent TGF- $\beta 1$ in BAL fluid was converted to its active forms using $1 \mathrm{~N} \mathrm{HCl}$ and the total of latent and active forms were reported. A microplate reader (Spectra MAX 190; Molecular Devices, Sunnyvale, Calif., USA) measured absorbance at $450 \mathrm{~nm}$, while total protein in BAL fluid was measured by the BCA Protein Assay Kit (Pierce, Rockford, Ill., USA) [24].

\section{Histologic Examination}

After BAL, the lungs from each animal were removed and sections of each lobe (5 per animal) were stained with hematoxylin and eosin (HE), Masson's trichrome, smooth muscle actin and von Willebrand factor for microscopic examination. The HE stain was used to evaluate the severity of inflammation. Two pathologists who were blinded to the background of the samples assigned a total inflammation score for each section of lung parenchyma as follows: 0 , normal; 1, inflammatory infiltration of eosinophils, lymphocytes and neutrophils in $<25 \%$ of the entire section; 2 , inflammatory infiltrates in $25-50 \%$ of the entire section; and 3 , in $>50 \%$ of the entire section. The total inflammation score for each animal was calculated as the mean of the scores of five lung sections.

Masson's trichrome was used to determine the area of collagen deposition in the airways, defined as the area from the subepithelial basement membrane to the adventitia layer of each respiratory bronchiole. Smooth muscle actin was used to measure the average thickness of the ASM layer beneath the airway epithelial cell basement membrane at four sites tangential to each respiratory bronchiole. The von Willebrand factor was used to identify the number of blood vessels in the lamina propia (from the subepithelial basement membrane to the adventitia layer) of the respiratory bronchiole. Morphometry was performed using Image-Pro Plus software (Media Cybernetics, Silver Spring, Md., USA), which randomly examined at least 10 successive microscopic fields of respiratory bronchioles throughout the sections of each lobe (5 per animal).

\section{Immunohistochemical Staining of Alpha-Smooth Muscle}

Actin and von Willebrand Factor

Paraffin lung sections were dewaxed in xylene and rehydrated in a graded alcohol series. To detect the von Willebrand factor, antigen retrieval was done with protease 1 reagent (Ventana Medical Systems, Tucson, Ariz., USA) for $20 \mathrm{~min}$ at $37^{\circ} \mathrm{C}$. Alphasmooth muscle actin staining was performed without antigen retrieval procedure. Sections were followed by rinsing in phosphatebuffered saline/Tween (PBST) and incubation in Protein Block ${ }^{\mathrm{TM}}$ solution (BioGenex; San Ramon, Calif., USA) for 20 min at room temperature. The primary antibody mouse anti-alpha-smooth muscle actin (1:100 dilution; Dako, Glostrup, Denmark) and rabbit anti-von Willebrand factor antibody (1:200 dilution; Dako) diluted in antibody diluents (Zymed Laboratories, San Francisco, Calif., USA) were then applied for $1 \mathrm{~h}$ at room temperature.

Endogenous peroxidase activity was quenched with 3\% hydrogen peroxide in methanol (Merck, Darmstadt, Germany) for 10 min at room temperature. The Super Sensitive ${ }^{\mathrm{TM}}$ Non-Biotin HRP Detection System (BioGenex) was used as the secondary antibody/ detection system. Briefly, sections were rinsed in PBST, incubated with Super Enhancer ${ }^{\mathrm{TM}}$ reagent (BioGenex) for $20 \mathrm{~min}$ at room temperature, rinsed in PBST and incubated in Polymer-HRP reagent (BioGenex) for $30 \mathrm{~min}$ at room temperature. Color was de- veloped using 3,3-diaminobenzidine (BioGenex) chromogen solution for $5 \mathrm{~min}$ at room temperature, followed by rinsing in PBST and counter-staining with hematoxylin.

\section{RNA Isolation and Real-Time Reverse Transcription}

Polymerase Chain Reaction Assay

Expressions of IL-4, IL-5, IL-10, IL-13, TNF- $\alpha$, inducible nitric oxide synthase (iNOS), TGF- $\beta 1$, VEGF-A and $\beta$-actin mRNA were examined using real-time reverse transcription polymerase chain reaction (RT-PCR) assay. Total RNA was extracted from lung tissue samples using an RNeasy mini kit (Qiagen $\mathrm{GmbH}$, Hilden, Germany). The first strand of cDNA was reverse-transcribed from RNA using Clontech's Advantage RT-for-PCR kit (Clontech-Takara Bio, Mountain View, Calif., USA). Each $50 \mu$ l of PCR reaction volume contained $25 \mu$ of $2 \times$ TaqMan Universal PCR Master Mix, $2.5 \mu \mathrm{l}$ of $20 \times$ TaqMan probe (Applied Biosystems, Foster City, Calif., USA) and $100 \mathrm{ng}$ of cDNA. Each PCR reaction was done in triplicate using an ABI Prism 7000 sequence detection system (Applied Biosystems).

Fluorescence was quantified as a Ct value, defined as the cycle number in which the detected fluorescence exceeded the threshold value. mRNA expression was reported as the ratio of target Ct over $\beta$-actin Ct. Data were presented as the fold change between the experimental and control groups [24].

\section{Western Blot Analysis}

Total protein was extracted from lung tissue samples. Protein was analyzed using 4-12\% NuPAGE Bis-Tris Gels (Invitrogen, Carlsbad, Calif., USA) and transferred onto polyvinylidene difluoride membranes (Millipore, Billerica, Mass., USA), which were blocked with $4 \%$ bovine serum albumin (Sigma, St. Louis, Mo., USA) in TBST for $1 \mathrm{~h}$ and probed with antibody at $4^{\circ} \mathrm{C}$ overnight. Antibodies against Akt, phosphorylated (p-)Akt (Ser473), GSK$3 \alpha / \beta$, p-GSK-3 $\beta$ (Ser9), mTOR, p-mTOR (Ser2448), 4E-BP1, p-4E-BP1 (Thr37/46), eIF4E, p-eIF4E (Ser209), ERK1/2 and pERK1/2 (Thr202/Tyr204) were all purchased from Cell Signaling Technology (Beverly, Mass., USA).

Antibodies against eIF2Be, p-eIF2Be (Ser539) and cyclin D1 were purchased from GeneTex (Irvine, Calif., USA) and Epitomics (Burlingame, Calif., USA), respectively. $\beta$-Actin was purchased from Novus Biologicals (Littleton, Colo., USA). Bound antibodies were detected using horseradish peroxidase-conjugated anti-rabbit secondary antibody (1:2,000 dilution; Cell Signaling Technology) or horseradish peroxidase-conjugated anti-mouse IgG (1:3,000 dilution; Jackson ImmunoResearch Laboratories, West Grove, Pa., USA) for $1 \mathrm{~h}$. Target protein bands were revealed using the enhanced chemiluminescence (Millipore). The images were captured using a Fusion FX7 imaging system (Vilber-Lourmat, Marne-la-Vallée, France) and quantified by the National Institutes of Health Image J software. Target protein bands were normalized against $\beta$-actin. Data were presented as the fold change between the experimental and control groups [25].

\section{Data Analysis}

Student's t test and analysis of variance (ANOVA) were used for statistical analysis, where appropriate, using SPSS for Windows (version 14.0; SPSS Inc., Chicago, Ill., USA). If ANOVA showed statistical significance, Scheffe's test was performed. All values were expressed as the mean \pm standard deviation. Significance was set at $\mathrm{p}<0.05$. 

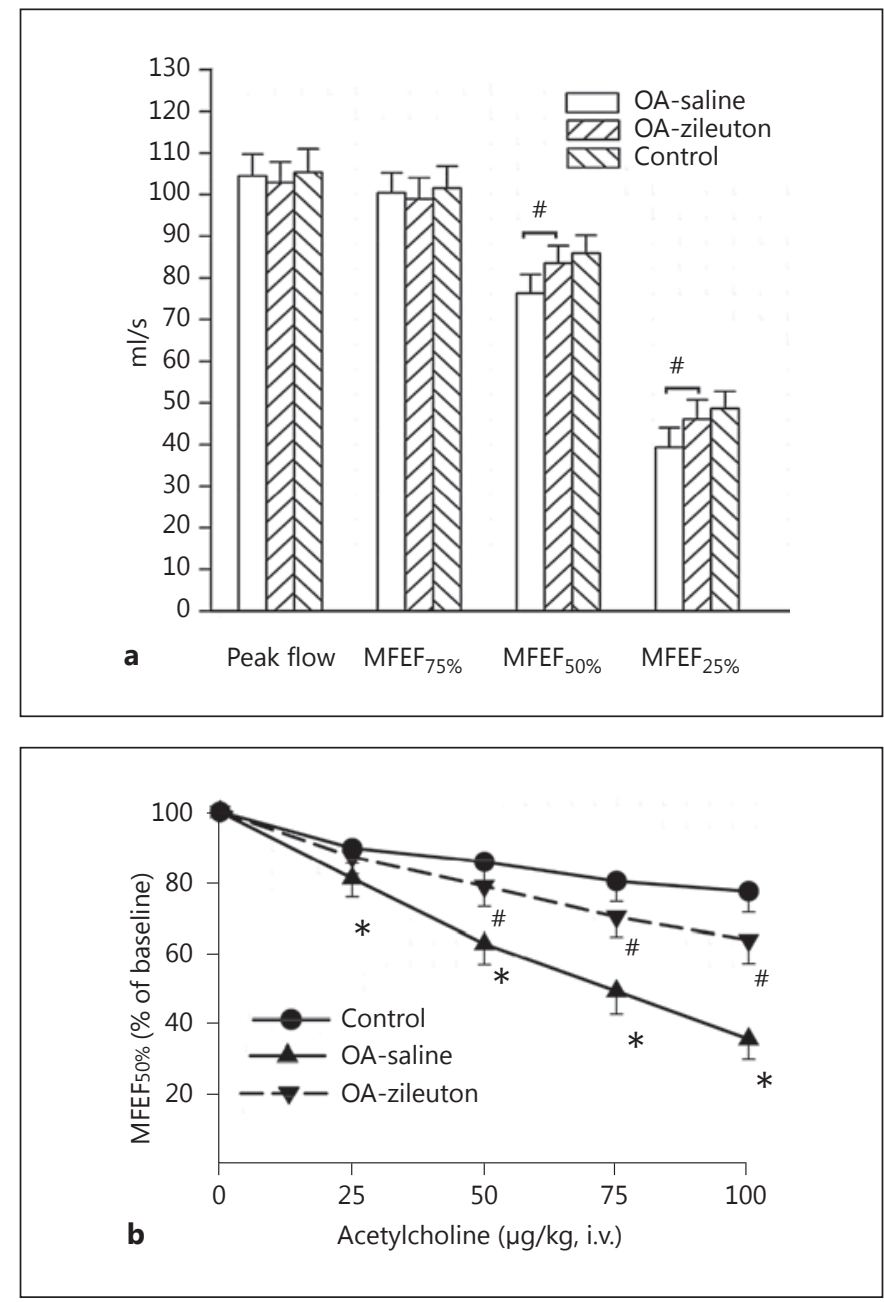

Fig. 1. a $\mathrm{MFEF}_{50 \%}$ and $\mathrm{MFEF}_{25 \%}$ were significantly lower in the OA-saline group than in the other two groups on day 31 . $^{*} \mathrm{p}<0.05$ comparing the OA-saline and OA-zileuton groups. b Dose-response curves of $\mathrm{MFEF}_{50 \%}$ in the three groups of brown Norway rats. The percentage change of $\mathrm{MFEF}_{50 \%}$ from baseline in the OAsaline group was higher than that of the other two groups at tested acetylcholine doses $(25-100 \mu \mathrm{g} / \mathrm{kg})$. The percentage change of $\mathrm{MFEF}_{50 \%}$ from baseline in the OA-zileuton group was higher than that of the control group at tested acetylcholine doses $(50-100 \mu \mathrm{g} /$ $\mathrm{kg}$ ) on day $31 .{ }^{*} \mathrm{p}<0.05$ comparing the three groups; ${ }^{*} \mathrm{p}<0.05$ comparing the OA-zileuton and control groups.

\section{Results}

\section{Pulmonary Function Tests}

There was no difference in TLC (OA-saline group, 13.7 $\pm 1.4 \mathrm{ml}$; OA-zileuton group, $13.8 \pm 1.2 \mathrm{ml}$; control group, $14.1 \pm 1.6 \mathrm{ml}$ ) among the three groups at baseline. The mean peak flow and $\mathrm{MFEF}_{75 \%}$ did not differ significantly among the three groups at baseline. The $\mathrm{MFEF}_{50 \%}$ and
Table 1. Total and differential cell counts, cytokines and total protein levels in BAL fluid

OA-zileuton OA-saline Control

$(\mathrm{n}=10) \quad(\mathrm{n}=10) \quad(\mathrm{n}=10)$

Total cell count $\left(\times 10^{4}\right) / \mathrm{ml} \quad 3.52 \pm 0.73^{\mathrm{a}} \quad 9.84 \pm 2.06^{\mathrm{b}} \quad 1.05 \pm 0.22$

Macrophages $\left(\times 10^{4}\right) / \mathrm{ml} \quad 2.69 \pm 0.58^{\mathrm{a}} \quad 5.48 \pm 1.25^{\mathrm{b}} \quad 0.95 \pm 0.18$

Lymphocytes $\left(\times 10^{4}\right) / \mathrm{ml} \quad 0.32 \pm 0.06^{\mathrm{a}} \quad 1.85 \pm 0.36^{\mathrm{b}} \quad 0.05 \pm 0.02$

Neutrophils $\left(\times 10^{4}\right) / \mathrm{ml} \quad 0.07 \pm 0.02^{\mathrm{a}} \quad 0.23 \pm 0.05^{\mathrm{b}} \quad 0.02 \pm 0.01$

Eosinophils $\left(\times 10^{4}\right) / \mathrm{ml} \quad 0.44 \pm 0.09^{\mathrm{a}} \quad 2.28 \pm 0.43^{\mathrm{b}} \quad 0.03 \pm 0.01$

IL-10, pg/ml

IL-13, pg/ml

TGF- $\beta 1, \mathrm{pg} / \mathrm{ml}$

$15.6 \pm 5.1^{\mathrm{a}}$

$30.2 \pm 9.1^{\mathrm{b}} \quad 8.4 \pm 2.4$

VEGF, pg/ml

$20.7 \pm 6.4^{\mathrm{a}} \quad 39.8 \pm 10.7^{\mathrm{b}} 11.4 \pm 3.9$

$11.2 \pm 3.1^{\mathrm{a}} \quad 19.4 \pm 5.3^{\mathrm{b}} \quad 6.6 \pm 1.8$

$36.7 \pm 8.2^{\mathrm{a}} \quad 66.8 \pm 10.4^{\mathrm{b}} \quad 15.5 \pm 6.5$

Protein, $\mu \mathrm{g} / \mathrm{ml}$

$174.4 \pm 41.7^{\mathrm{a}} \quad 348.3 \pm 74.3^{\mathrm{b}} \quad 98.6 \pm 22.9$

ANOVA and Scheffe tests were used. The OA-zileuton group was treated with $25 \mathrm{mg} / \mathrm{kg} /$ day of zileuton; the OA-saline group was sensitized with OA but treated with saline only.

a Significant differences in the cell counts, cytokines and total protein levels of the OA-zileuton group compared to the control group $(\mathrm{p}<0.05)$

${ }^{b}$ Significant differences in cell counts, cytokines and total protein levels of the OA-zileuton and control groups compared to the OA-saline group $(\mathrm{p}<0.05)$.

$\mathrm{MFEF}_{25 \%}$ were significantly lower in the OA-saline group than in the other two groups, but did not differ between the OA-zileuton and control groups (fig. 1a). At the acetylcholine doses tested $(25-100 \mu \mathrm{g} / \mathrm{kg})$, the percentage change in $\mathrm{MFEF}_{50 \%}$ was significantly higher and PD20MFEF $50 \%$ Ach was significantly lower in the OA-saline group than in the other two groups. At higher doses of acetylcholine tested $(50-100 \mu \mathrm{g} / \mathrm{kg})$, the percent change in $\mathrm{MFEF}_{50 \%}$ was significantly higher and $\mathrm{PD} 20 \mathrm{MFEF}_{50 \%}$ Ach was significantly lower in the OAzileuton group than in the control group (fig. 1b).

\section{Bronchoalveolar Lavage}

There was no difference in the amount of BAL fluid recovered from the three groups $(85.4 \pm 2.7$ vs. $85.5 \pm 2.9$ vs. $86.4 \pm 3.2 \%)$. The OA-saline group had a higher total cell count and absolute count of each cell type than the other two groups (table 1), and the OA-zileuton group had higher total cell counts and higher absolute counts of each cell type than the controls (table 1). The OA-saline group had higher IL-10, IL-13, TGF- $\beta 1$, VEGF cytokine and total protein levels in BAL fluid than the other two groups (table 1), and the OA-zileuton group had higher IL-10, IL-13, TGF- $\beta 1$, VEGF cytokine and total protein levels in BAL fluid than the controls (table 1). 


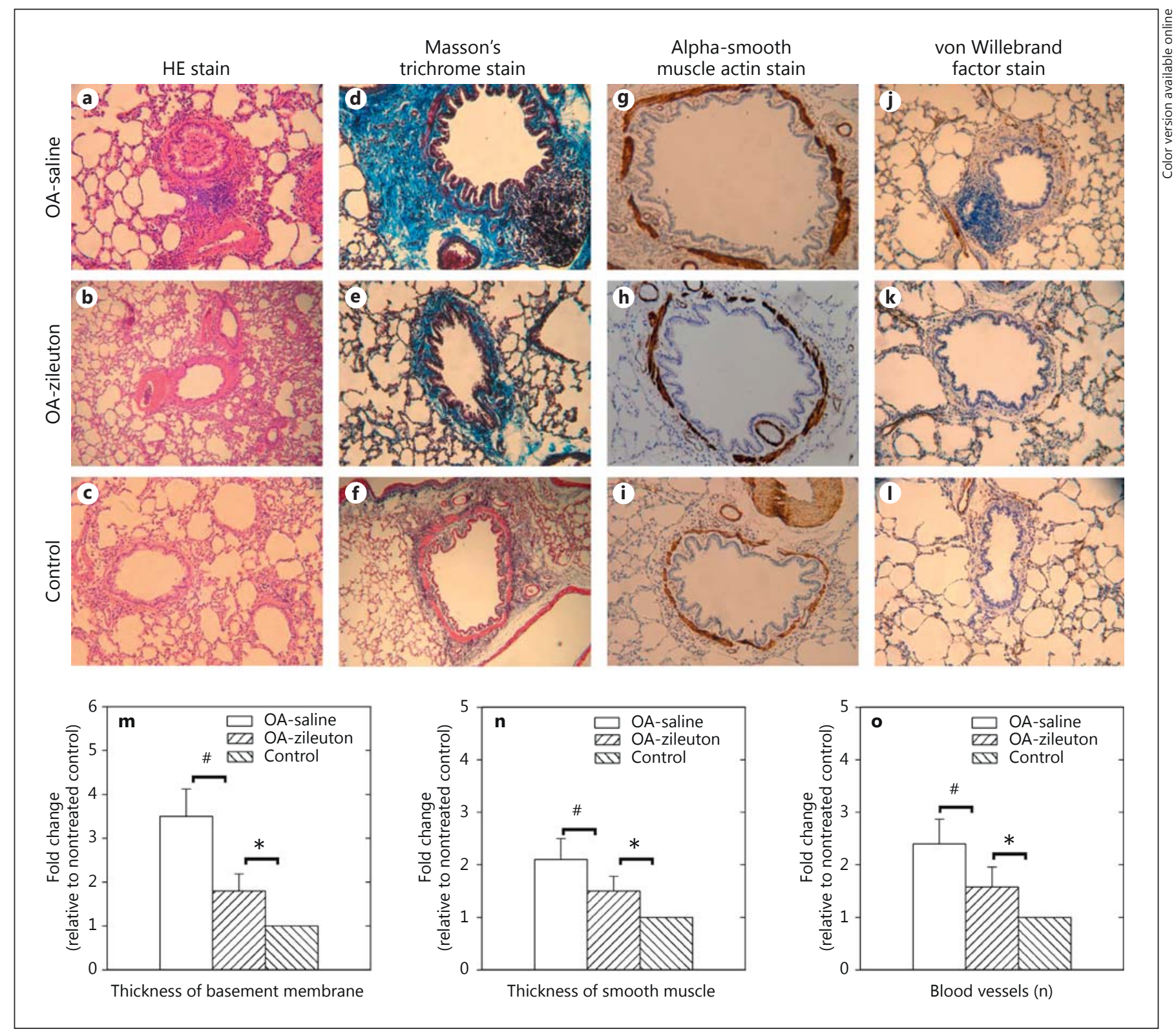

Fig. 2. Histopathology of airway remodeling (respiratory bronchioles) in photographs representing the four experiments. a-c HE stain. $\times 100$. d-f Masson's trichrome stain. $\times 100$. g-i Alpha-smooth muscle actin stain. $\times 100$. $\mathbf{j}-\mathbf{I}$ von Willebrand factor stain. $\times 100$. $\mathbf{m}$ Mean area of collagen deposition surrounding the airways (respiratory bronchioles). $\mathbf{n}$ Mean thickness of the smooth muscle layer. o The mean number of the blood vessels surrounding the airways was lower in the control group than in the OA-zileuton group, which was significantly lower than in the OA-saline group on day 31. ${ }^{\#} \mathrm{p}<0.05$ comparing the OA-saline and OA-zileuton groups; ${ }^{*} \mathrm{p}<0.05$ comparing the $\mathrm{OA}$-zileuton and control groups.

tration in the lung tissues and airways of the OA-zileuton group (fig. 2b), while the control group had no inflammatory reaction (fig. $2 \mathrm{c}$ ). The mean inflammatory scores in the OA-saline group was higher than those of the OAzileuton and control groups (OA-saline group, $2.2 \pm 0.5$; OA-zileuton group, $1.4 \pm 0.4$; control group, 0 ; $\mathrm{p}<0.05$ ). 


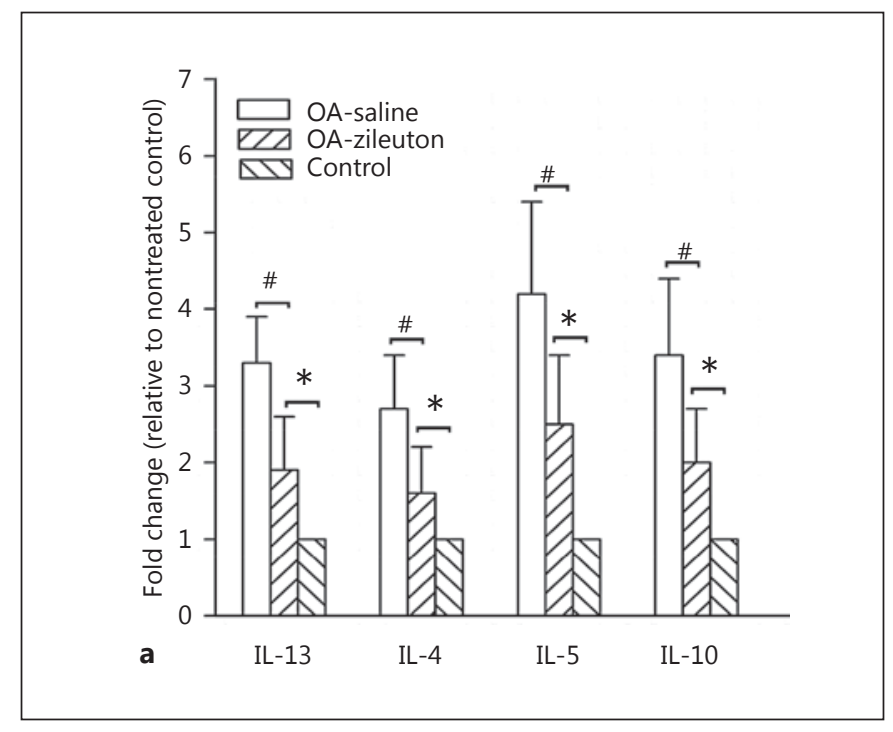

Fig. 3. On day 31 , relative changes in IL-4, IL-5, IL-10 and IL-13 mRNA expressions (a) and relative changes in VEGF, iNOS, TNF- $\alpha$ and TGF- $\beta 1$ mRNA expressions (b) in lung tissues of the $\mathrm{OA}$-saline group were greater than those in the OA-zileuton group,

The area of collagen deposition surrounding the airways was lowest in the control group compared to those of the other two groups and was significantly lower in the OA-zileuton group compared to the OA-saline group. The mean fold change of the mean area of airway collagen deposition surrounding the airways relative to the control group was 1.8-fold in the OA-zileuton group and 3.7-fold in OA-saline group (fig. $2 \mathrm{~d}-\mathrm{f}, \mathrm{m}$ ). The mean thickness of the smooth muscle layer surrounding the airways was lowest in the control group compared to the other two groups, and was significantly decreased in the OA-zileuton group compared to the OA-saline group. The mean fold change in mean thickness of the smooth muscle layer surrounding the airways relative to the control group was 1.5 -fold in the OA-zileuton group and 2.1-fold in the OA-saline group (fig. $2 \mathrm{~g}-\mathrm{i}, \mathrm{n}$ ).

The mean number of blood vessels surrounding the airways was lowest in the control group compared to the other two groups and was significantly lower in the OAzileuton group than in the OA-saline group. The mean fold change in the mean number of blood vessels around the airways relative to the control group was 1.5 -fold in the OA-zileuton group and 2.3-fold in the OA-saline group (fig. $2 j-1$, o).

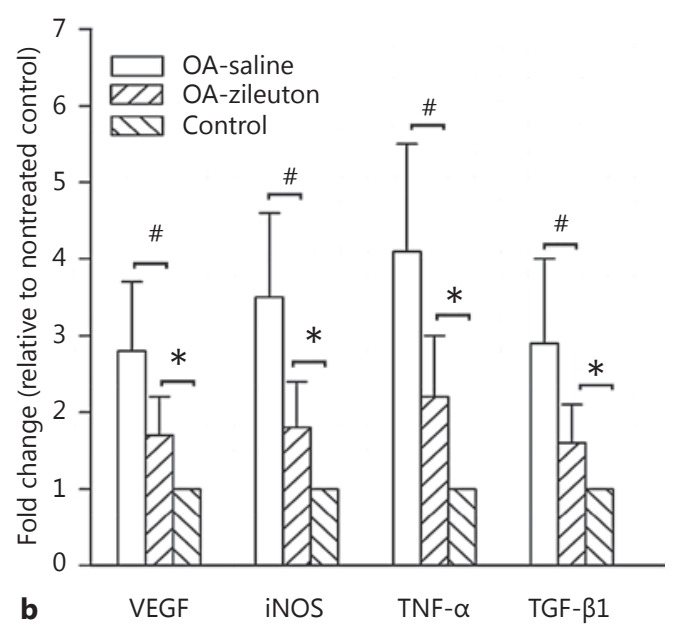

which were greater than those of the control group. ${ }^{\#} \mathrm{p}<0.05$ comparing the OA-saline and OA-zileuton groups; ${ }^{*} \mathrm{p}<0.05$ comparing the OA-zileuton and control groups.

\section{Cytokine mRNA Profile Using Real-Time RT-PCR in}

Lung Tissue

Real-time RT-PCR of IL-4, IL-5, IL-10, IL-13, TNF- $\alpha$, iNOS, TGF- $\beta 1$ and VEGF-A mRNA expressions were consistently lower in the control group than in the other two groups and were significantly lower in the OA-zileuton group than in the OA-saline group (fig. 3a, b).

\section{Western Blot Analysis on ERK and PI3K Pathways}

p-Akt, p-GSK-3 $\beta$, p-eIF2Be, p-mTOR, p-4E-BP1 and p-eIF4E levels were consistently lower in the control group compared to the other two groups and significantly lower in the OA-zileuton group compared to the OA-saline group (fig. $4 a-f, i, j$ ). Zileuton did not inhibit OA-induced phosphorylation of ERK1/2 (fig. 4g, j). Cyclin D1 was lowest in the control group compared to the other two groups and significantly lower in the OAzileuton group compared to the OA-saline group (fig. $4 h, j)$.

\section{Discussion}

This study demonstrates that brown Norway rats in the OA-saline group after sensitization and repeated allergen challenge have increased BHR, airway inflamma- 


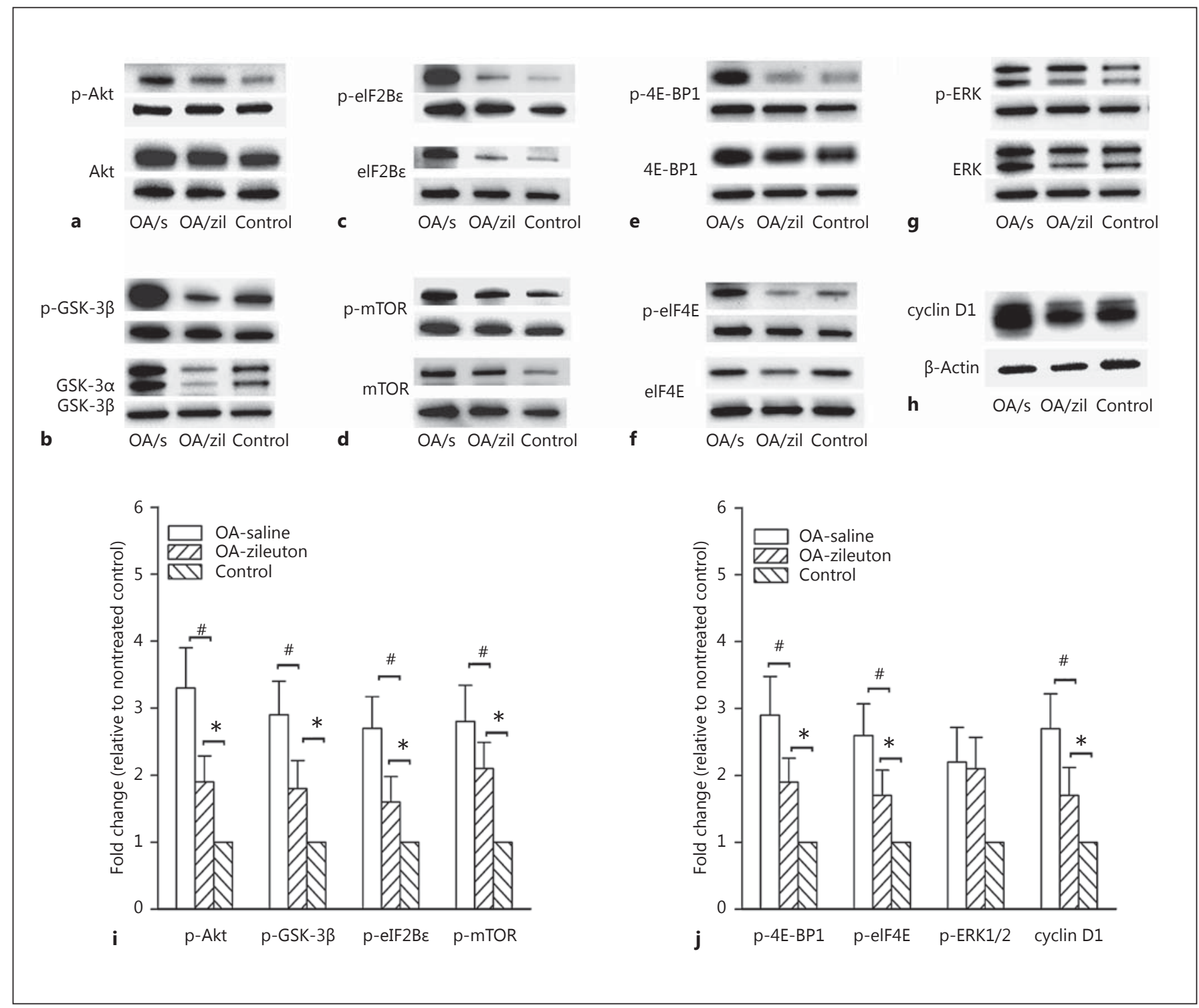

Fig. 4. a-h Western blot analysis on ERK and PI3K pathways in the photographs represent the 3 experiment groups. $\mathbf{i}$, j Relative changes of p-Akt, p-GSK-3 $\beta$, p-eIF2B $\varepsilon, p$-mTOR, p-4E-BP1, p-eIF4E and cyclin D1 in lung tissues of OA-sensitized brown Norway rats were greater than those in the other two groups, and the relative

tion, Th2-related cytokine, TGF- $\beta$, VEGF and Th2-related cytokine mRNA expression, and increased smooth muscle layer thickness surrounding the airways compared to those in the control group. Moreover, rats in the OA-zileuton group have decreased BHR, airway inflammation, IL-10, IL-13, TGF- $\beta 1$, VEGF cytokine level in BAL fluid, decreased IL-4, IL-5, IL-10, IL-13, TGF- $\beta 1$, VEGF, TNF- $\alpha$ and iNOS mRNA expressions, and de-

changes in the OA-zileuton group were greater than those of the control group. There was no significant difference in p-ERK1/2 in lung tissues between the OA-saline and OA-zileuton groups on day 31. ${ }^{*} \mathrm{p}<0.05$ comparing the OA-saline and OA-zileuton groups; ${ }^{*} \mathrm{p}<0.05$ comparing the OA-zileuton and control groups.

creased smooth muscle thickness surrounding the airways than rats in the OA-saline group.

Whether or not ASM hypertrophy is present in asthma remains controversial $[8,9,26]$. This study demonstrates that p-Akt, p-mTOR, p-GSK-3 $\beta$, p-eIF2B $\varepsilon, \mathrm{p}-4 \mathrm{E}-\mathrm{BP} 1$ and $\mathrm{p}$-eIF4E are highest in the OA-saline group compared to the other two groups and are significantly lower in the OA-zileuton group than in the OA-saline group. This im- 
plies that OA can induce ASM cell hypertrophy, which is prevented by zileuton. Ebina et al. [9] showed that one of the two subtypes of fatal asthmatics is characterized by thickened ASM distributed over the entire airway, with prevalent hypertrophy. Benayoun et al. [8] have shown that patients with asthma have larger ASM cell diameter compared to control subjects in bronchial biopsies. Furthermore, using an ultrastructural approach, severe asthmatics have been shown to have the highest ASM cell size. Begueret et al. [26] also reported increased ASM cell size in atopic asthmatics. Thus, ASM cell hypertrophy is present in and may be related to severe asthma.

There is much evidence showing an increased proliferation rate of asthmatic ASM cells compared to nonasthmatics in vitro and in vivo [27-29]. A recent study revealed that $\mathrm{PI} 3 \mathrm{~K}$ is the predominant pathway leading to ASM cell proliferation in asthmatic patients [28]. The present study demonstrates that PI3K, p-Akt, and cyclin $\mathrm{D} 1$ are highest in the OA-saline group compared to the other two groups, and significantly lower in the OAzileuton group than in the OA-saline group. In contrast, zileuton does not influence the OA-induced phosphorylation of ERK1/2. Cyclin D1 is an important protein regulator of the early G1 phase of the cell cycle [25]. Results imply that OA can activate PI3K and p-Akt to increase cyclin D1 expression and induce ASM cell hyperplasia. In contrast, zileuton prevents PI3K and p-Akt activation, inhibits cyclin D1 expression and prevents OA-induced ASM cell hyperplasia.

The results here are consistent with those of previous studies. Salmon et al. [30] have shown that repeated allergen exposure of sensitized brown Norway rats induces airway cell DNA synthesis and remodeling, while Henderson et al. [31] have shown that the cysteinyl leukotriene1 receptor antagonist, Montelukast, significantly reduces airway eosinophil infiltration, mucus plugging, smooth muscle hyperplasia and subepithelial fibrosis in OA-sensitized or OA-challenged mice. Jeffery [22] reported that leukotriene receptor antagonists may be anti- inflammatory and may be able to reduce bronchial smooth muscle proliferation.

There is substantial evidence showing that IL-13 and TGF- $\beta$ are related to remodeling. Their effects are reduced by zileuton, thereby reducing airway remodeling in OA-treated animals $[22,31]$. This study also demonstrates that the IL-13, TGF- $\beta$ and VEGF cytokine levels, the IL-13, TGF- $\beta$ and VEGF mRNA expressions, the area of collagen deposition and the mean number of blood vessels surrounding the airways are lowest in the control group than in the other two groups. They are significantly lower in the OA-zileuton group than in the OA-saline group. These results imply that OA can induce increased airway ECM, which can be prevented by zileuton. Collagen deposition and angiogenesis are associated with increased ECM, both in early and in mild bronchial asthma $[30,32]$. Even minimally increased ECM and the effects of marginal submucosal thickening in the presence of maximal muscular contraction may cause severe airflow impairment [33-37]. The present study shows that zileuton inhibits OA-stimulated increase in ASM mass by inhibiting hypertrophy, hyperplasia and ECM through the PI3K/Akt pathway, thereby reducing cyclin D1 expression.

In conclusion, $\mathrm{OA}$ induces increased airway inflammation and ASM mass. Zileuton is effective in preventing inflammatory response and ASM remodeling in rats after sensitization and repeated allergen challenge, thereby attenuating BHR. Zileuton inhibits OA-stimulated increase in ASM mass by inhibiting hypertrophy, hyperplasia and ECM via the PI3K/Akt pathway to reduce cyclin D1 expression.

\section{Acknowledgements}

This work was supported in part by a grant from the National Science Council (grant NSC 88-2314-B-195-009-M50).

References

Davies DE, Wicks J, Powell RM, Puddicombe SM, Holgate ST: Airway remodeling in asthma: new insights. J Allergy Clin Immunol 2003;111:215-225.

2 Hamid Q: Pathogenesis of small airways in asthma. Respiration 2012;84:4-11.

-3 Pepe C, Foley S, Shannon J, Lemiere C, Olivenstein R, Ernst P, Ludwig MS, Martin JG, Hamid Q: Differences in airway remodeling between subjects with severe and moderate asthma. J Allergy Clin Immunol 2005;116:544-549.

4 Kaminska M, Foley S, Maghni K, StornessBliss C, Coxson H, Ghezzo H, Lemière C, Olivenstein R, Ernst P, Hamid Q, Martin J: Airway remodeling in subjects with severe asthma with or without chronic persistent airflow obstruction. J Allergy Clin Immunol 2009;124:45-51. 
5 5 Roth M, Johnson PR, Borger P, Bihl MP, Rüdiger JJ, King GG, Ge Q, Hostettler K, Burgess JK, Black JL, Tamm M: Dysfunctional interaction of $\mathrm{C} / \mathrm{EBP} \alpha$ and the glucocorticoid receptor in asthmatic bronchial smooth-muscle cells. N Engl J Med 2004;351:560-574.

-6 Hollins F, Kaur D, Yang W, Cruse G, Saunders R, Sutcliffe A, Berger P, Ito A, Brightling $\mathrm{CE}$, Bradding P: Human airway smooth muscle promotes human lung mast cell survival, proliferation, and constitutive activation: cooperative roles for CADM1, stem cell factor, and IL-6. J Immunol 2008;181:2772-2780.

$\checkmark 7$ Girodet PO, Ozier A, Trian T, Begueret H, Ousova O, Vernejoux JM, Chanez P, Marthan R, Berger P, Tunon de Lara JM: Mast cell adhesion to bronchial smooth muscle in asthma specifically depends on CD51 and CD44 variant 6. Allergy 2010;65:1004-1012.

-8 Benayoun L, Druilhe A, Dombret MC, Aubier M, Pretolani M: Airway structural alterations selectively associated with severe asthma. Am J Respir Crit Care Med 2003;167:1360-1368.

>9 Ebina M, Takahashi T, Chiba T, Motomiya M: Cellular hypertrophy and hyperplasia of airway smooth muscles underlying bronchial asthma: a 3-D morphometric study. Am Rev Respir Dis 1993;148:720-726.

10 Bentley JK, Hershenson MB: Airway smooth muscle growth in asthma: proliferation, hypertrophy, and migration. Proc Am Thorac Soc 2008;5:89-96.

11 Zhou L, Goldsmith AM, Bentley JK, Jia Y, Rodriguez ML, Abe MK, Fingar DC, Hershenson $\mathrm{MB}$ : $4 \mathrm{E}$-binding protein phosphorylation and eukaryotic initiation factor-4E release are required for airway smooth muscle hypertrophy. Am J Respir Cell Mol Biol 2005;33:195202.

12 Deng H, Hershenson MB, Lei J, Bitar KN, Fingar DC, Solway J, Bentley JK: p70 Ribosomal S6 kinase is required for airway smooth muscle cell size enlargement but not increased contractile protein expression. Am J Respir Cell Mol Biol 2010;42:744-752.

13 Hardt SE, Tomita H, Katus HA, Sadoshima J: Phosphorylation of eukaryotic translation initiation factor $2 \mathrm{~B} \varepsilon$ by glycogen synthase kinase- $3 \beta$ regulates $\beta$-adrenergic cardiac myocyte hypertrophy. Circ Res 2004;94:926935.

14 Deng H, Dokshin GA, Lei J, Goldsmith AM, Bitar KN, Fingar DC, Hershenson MB, Bentley JK: Inhibition of glycogen synthase kinase$3 \beta$ is sufficient for airway smooth muscle hypertrophy. J Biol Chem 2008;283:1019810207.
15 Smith PG, Janiga KE, Bruce MC: Strain increases airway smooth muscle cell proliferation. Am J Respir Cell Mol Biol 1994;10:8590.

16 Tliba O, Panettieri RA Jr: Non-contractile functions of airway smooth muscle cells in asthma. Annu Rev Physiol 2009;71:509-535.

17 Engelman JA, Luo J, Cantley LC: The evolution of phosphatidylinositol 3-kinases as regulators of growth and metabolism. Nat Rev Genet 2006;7:606-619.

18 Peters-Golden M: Expanding roles for leukotrienes in airway inflammation. Curr Allergy Asthma Rep 2008;8:367-373.

19 Takemura M, Niimi A, Matsumoto H, Ueda T, Matsuoka H, Yamaguchi M, Jinnai $M$, Chin K, Mishima M: Clinical, physiological and anti-inflammatory effect of montelukast in patients with cough variant asthma. Respiration 2012;83:308-315.

20 Henderson WR Jr, Chiang GK, Tien YT, Chi EY: Reversal of allergen-induced airway remodeling by CysLT1 receptor blockade. Am J Respir Crit Care Med 2006;173:718-728.

21 Lee KS, Kim SR, Park HS, Park SJ, Min KH, Lee KY, Jin SM, Lee YC: Cysteinyl leukotriene up-regulates IL-11 expression in allergic airway disease of mice. J Allergy Clin Immunol 2007;119:141-149.

22 Jeffery P: Inflammation and remodeling in the adult and child with asthma. Pediatr Pulmonol Suppl 2001;21:3-16.

23 Israel E, Rubin P, Kemp JP, Grossman J, Pierson W, Siegel SC, Tinkelman D, Murray JJ, Busse W, Segal AT, Fish J, Kaiser HB, Ledford D, Wenzel S, Rosenthal R, Cohn J, Lanni C, Pearlman H, Karahalios P, Drazen JM: The effect of inhibition of 5-lipoxygenase by zileuton in mild-to-moderate asthma. Ann Intern Med 1993;119:1059-1066.

24 Lin CC, Liaw SF, Wu KM, Lin CH: Effect of erythromycin on bronchial hyperreactivity and inflammation in ovalbumin-sensitized brown Norway rats. Respir Physiol Neurobiol 2008; 161:267-272.

25 Chiou YL, Shieh JJ, Lin CY: Blocking of Akt/ $N F-\kappa B$ signaling by pentoxifylline inhibits platelet-derived growth factor-stimulated proliferation in Brown Norway rat airway smooth muscle cells. Pediatr Res 2006;60: 657-662.

26 Begueret H, Berger P, Vernejoux JM, Dubuisson L, Marthan R, Tunon-de-Lara JM: Inflammation of bronchial smooth muscle in allergic asthma. Thorax 2007;62:8-15.
27 Johnson PR, Roth M, Tamm M, Hughes M, Ge Q, King G, Burgess JK, Black JL: Airway smooth muscle cell proliferation is increased in asthma. Am J Respir Crit Care Med 2001; 164:474-477.

28 Burgess JK, Lee JH, Ge Q, Ramsay EE, Poniris $\mathrm{MH}$, Parmentier J, Roth M, Johnson PR, Hunt $\mathrm{NH}$, Black JL, Ammit AJ: Dual ERK and phosphatidylinositol 3-kinase pathways control airway smooth muscle proliferation: differences in asthma. J Cell Physiol 2008;216:673-679.

- 29 Borger P, Miglino N, Baraket M, Black JL, Tamm M, Roth M: Impaired translation of CCAAT/enhancer binding protein alpha mRNA in bronchial smooth muscle cells of asthmatic patients. J Allergy Clin Immunol 2009;123:639-645.

- 30 Salmon M, Walsh DA, Koto H, Barnes PJ, Chung KF: Repeated allergen exposure of sensitized Brown-Norway rats induces airway cell DNA synthesis and remodelling. Eur Respir J 1999;14:633-641.

- 31 Henderson WR Jr, Tang LO, Chu SJ, Tsao SM, Chiang GK, Jones F, Jonas M, Pae C, Wang H, Chi EY: A role for cysteinyl leukotrienes in airway remodeling in a mouse asthma model. Am J Respir Crit Care Med 2002; 165:108-116.

-32 Palmans E, Pauwels RA, Kips JC: Repeated allergen exposure changes collagen composition in airways of sensitised Brown Norway rats. Eur Respir J 2002;20:280-285.

33 Espinosa K, Bossé Y, Stankova J, Rola-Pleszczynski M: CysLT1 receptor up-regulation by TGF- $\beta$ and IL- 13 is associated with bronchial smooth muscle cell proliferation in response to LTD4. J Allergy Clin Immunol 2003;111: 1032-1040.

34 Wilson JW, Hii S: The importance of the airway micro-vasculature in asthma. Curr Opin Allergy Clin Immunol 2006;6:51-55.

35 James AL, Paré PD, Hogg JC: The mechanics of airway narrowing in asthma. Am Rev Respir Dis 1989;139:242-246.

- 36 Lee CG, Link H, Baluk P, Homer RJ, Chapoval S, Bhandari V, Kang MJ, Cohn L, Kim YK, McDonald DM, Elias JA: Vascular endothelial growth factor (VEGF) induces remodeling and enhances $\mathrm{T}_{\mathrm{H}} 2$-mediated sensitization and inflammation in the lung. Nat Med 2004; 10:1095-1103.

37 Grainge CL, Lau LC, Ward JA, Dulay V, Lahiff G, Wilson S, Holgate S, Davies DE, Howarth PH: Effect of bronchoconstriction on airway remodeling in asthma. N Engl J Med 2011;364:2006-2015. 